\title{
Adequacy of haemodialysis and or haemofiltration treatments for patients with acute kidney injury Andrew Davenport
}

Address: Centre for Nephrology, University College London Medical School, Royal Free Campus, Rowland Hill Street, London NW3 2PF, UK Email: andrew.davenport@royalfree.nhs.uk

FI000 Medicine Reports 2010, 2:33 (doi:10.3410/M2-33)

The electronic version of this article is the complete one and can be found at: http://fl000.com/reports/medicine/content/2/33

\begin{abstract}
Traditionally, the dose of haemodialysis or haemofiltration delivered to patients with kidney failure is assessed by urea clearance. For patients with chronic kidney disease below a critical urea clearance threshold, patient wellbeing is compromised. It was suggested, therefore, that the dose of dialysis or haemofiltration delivered could also affect outcomes for patients with acute kidney injury. Two major prospective multicentre clinical trials have recently reported that a higher intensity of renal support, by either intermittent haemodialysis or continuous renal replacement therapy, did not improve patient survival or recovery from dialysis. It must be recognised, however, that urea clearance is only one component of renal supportive therapy, and other aspects, including volume control, electrolyte homeostasis and acid-base balance, may be equally important targets for patients with acute kidney injury.
\end{abstract}

\section{Introduction and context}

The National Cooperative Dialysis Study, the first randomised controlled study of dialysis dose, defined an 'adequacy' threshold for end-stage chronic kidney disease patients receiving chronic haemodialysis [1] based on the dialyser clearance of urea, a small solute marker of nitrogen turnover, which was defined in terms of a dimensionless parameter known as the normalised urea clearance, or $\mathrm{Kt} / \mathrm{V}$ ( $\mathrm{K}$, dialyzer urea clearance; $\mathrm{t}$, dialysis session duration; and $\mathrm{V}$, urea volume distribution). Below a sessional threshold $\mathrm{Kt} / \mathrm{V}$ of 0.9 for standard thrice-weekly schedules, complication-free survival was compromised within months [2]. Subsequent observational studies suggested that higher doses resulted in improved longerterm outcomes $[3,4]$, and by consensus the minimum target $\mathrm{Kt} / \mathrm{V}$ was raised to 1.2 [5]. A subsequent prospective randomised controlled study, the Hemodialysis (HEMO) study, reported that higher doses did not appear to further improve outcome [6]. However, subgroup analysis suggested that women may benefit from higher Kt/V doses, fuelling suggestions that using standard Kt/V targets to prescribe dialysis may lead to under-dosing in women and small men [7]. These studies suggest that, for standard thrice-weekly therapy, medium-term survival (measured in months) is dependent on achieving a minimum level of small solute removal, as defined by the National Cooperative Dialysis Study.

Just as the amount of dialysis delivered to patients with end-stage chronic kidney disease is important in determining survival, it was reported that the dose of intermittent haemodialysis or continuous renal replacement therapy (CRRT) was also important in determining survival in patients with acute kidney injury (AKI) [8-10], although this was not a universal finding [11]. As patients with AKI continue to have high mortality, and evidencebased clinical management is somewhat limited [12], two prospective multicentre trials were designed to investigate the effect of dose of renal replacement therapy on outcome in patients with AKI $[13,14]$.

\section{Recent advances}

The Veterans Affairs/National Institutes of Health (VA/NIH) study essentially randomised patients to 
initially receive either an intensive or less intensive dose of intermittent haemodialysis, or an intensive or less intensive dose of CRRT [13], depending upon severity of illness at the time of randomisation. (During the course of the study patients were switched between treatment modalities according to haemodynamic stability.) During haemofiltration, it is assumed that urea is effectively cleared (to the extent that the concentration in the effluent ultrafiltrate is equal to that of plasma water) so that urea clearance can simply be assessed by the total ultrafiltration volume achieved. In this study, more intensive renal replacement therapy did not show any survival advantage for either the intermittent haemodialysis or CRRT groups. However, the minimum haemodialysis target $\mathrm{Kt} / \mathrm{V}$ of 1.2 was somewhat higher than that typically prescribed for patients with AKI by the recruiting centres. In addition, there was no survival advantage for the haemofiltration cohort compared to those treated by dialysis. Haemofiltration clears solutes primarily by convection, thus removing a larger spectrum of solutes than haemodialysis, which predominantly clears small water soluble solutes by diffusion.

The second study, the RENAL (Randomised Evaluation of Normal versus Augmented Level of renal replacement therapy in ICU) study, assessed the effect of an augmented dose of CRRT (an ultrafiltration rate of $40 \mathrm{ml} / \mathrm{kg} / \mathrm{h}$ versus $25 \mathrm{ml} / \mathrm{kg} / \mathrm{h}$ ) [14]. Once again, this study failed to show any significant effect of dose of convective renal replacement therapy on patient outcomes, although the delivered dosages were less than that prescribed and both small patients $(<60 \mathrm{~kg})$ and very heavy patients $(>120 \mathrm{~kg})$ were excluded.

\section{Implications for clinical practice}

What implications do these studies have for the clinical management of patients with AKI? Although urea can dissociate to cyanate in plasma water and then form carbamylated products in a reversible fashion, with some analogy to glycosylation [15], it would appear that toxicity from the accumulation of small nitrogenous solutes is not the major determinant of short-term outcome (days to weeks) in patients with AKI.

AKI frequently occurs in the setting of multiple organ failure, and mortality remains high, with patient outcome typically dependent upon the severity of the underlying condition and associated co-morbidities. The replacement of organ function may play a critical short-term role in maintaining life in patients already destined by other factors to have the potential to recover. However, urea clearance is only one component of renal replacement therapies. For example, failure to correct persistent volume overload is associated with not only
Figure I. Schematic hypothetical representation of the time course for the accumulation of azotemic toxins in patients with both acute kidney injury and chronic kidney failure

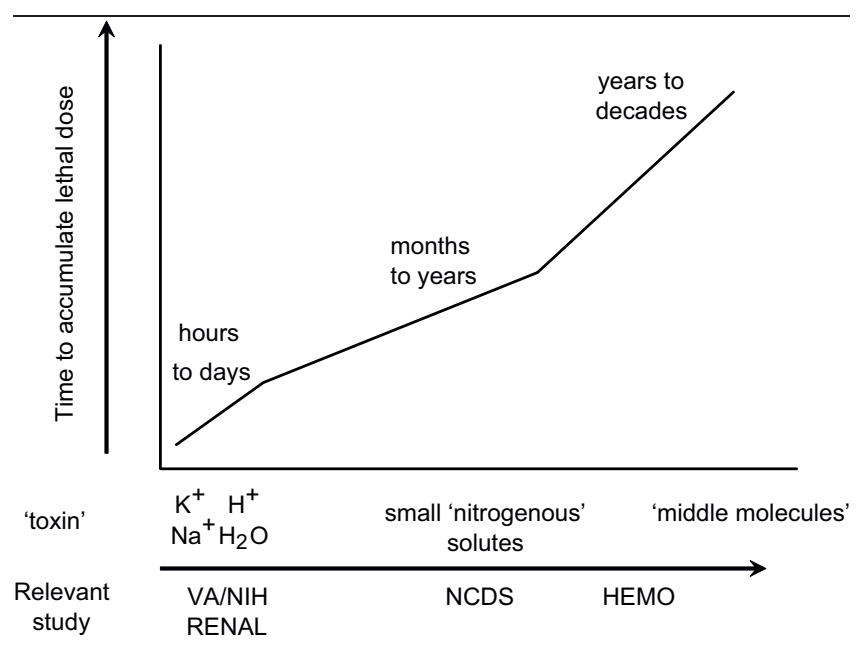

The schematic illustrates that different 'toxins' play a role over time, and as such may require different clinical management strategies. HEMO, Hemodialysis; NCDS, National Cooperative Dialysis Study; RENAL, Randomised Evaluation of Normal versus Augmented Level of renal replacement therapy in ICU; VA/NIH, Veterans Affairs/National Institutes of Health.

increased post-surgical morbidity [16], but also increased risk of AKI [17] and mortality [18]. Thus, for patients with AKI, the adequate removal of even smaller moieties than urea is the principal determinant of the 'adequacy' of renal replacement. These moieties are the neglected 'uraemic' toxins, including potassium, sodium, hydrogen ions and water [19] (Figure 1). The consequences of the accumulation of these moieties, hyperkalaemia, pulmonary oedema, and acidosis, may be lethal in minutes [20].

Although the delivery of higher doses of haemofiltration or more frequent haemodialysis did not improve overall outcome, higher volume CRRT exchange cycles and more frequent haemodialysis treatments will help correct acidosis, and may be appropriate during the initial resuscitation phase of AKI. Correction of volume overload may help explain the positive findings and improved clinical outcomes reported from some of the earlier trials of increased dose of renal support [9], compared to the more recent VA/NIH and RENAL studies, which had similar fluid balance targets.

\section{Abbreviations}

AKI, acute kidney injury; CRRT, continuous renal replacement therapy; RENAL, Randomised Evaluation of Normal versus Augmented Level of renal replacement 
therapy in ICU; VA/NIH, Veterans Affairs/National Institutes of Health.

\section{Competing interests}

The author declares that he has no competing interests.

\section{Acknowledgments}

The author wishes to thank Ken Farrington for his helpful comments.

\section{References}

I. Lowrie EG, Laird NM, Parker TF, Sargent JA: Effect of the haemodialysis prescription of patient morbidity: report from the National Cooperative Dialysis Study. $N$ Engl J Med 198I, 305: I|76-8I.

2. Gotch FA, Sargent JA: A mechanistic analysis of the National Cooperative Dialysis Study (NCDS). Kidney Int 1985, 28:526-34.

3. Parker TF 3rd, Husni L, Huang W, Lew N, Lowrie EG: Survival of haemodialysis patients in the United States is improved with a greater quantity of dialysis. Am J Kidney Dis 1994, 23:670-80.

4. Held PJ, Port FK, Wolfe RA, Stannard DC, Carroll CE, Daugirdas JT, Bloembergen WE, Greer JW, Hakim RM: The dose of hemodialysis and patient mortality. Kidney Int 1996, 50:550-6.

5. Morbidity and mortality of dialysis. NIH Consens Statement 1993, II:I-33.

6. Eknoyan G, Beck GJ, Cheung AK, Daugirdas JT, Greene T, Kusek JW, Allon M, Bailey J, Delmez JA, Depner TA, Dwyer JT, Levey AS, Levin NW, Milford E, Ornt DB, Rocco MV, Schulman G, Schwab SJ, Teehan BP, Toto R; Haemodialysis (HEMO) Study Group: Effect of dialysis dose and membrane flux in maintenance haemodialysis. N Engl J Med 2002, 347:2010-9.

7. Spalding EM, Chandna SM, Davenport A, Farrington $\mathrm{K}$ : Kt/V underestimates the haemodialysis dose in women and small men. Kidney Int 2008, 74:348-55.

8. Ronco C, Bellomo R, Homel P, Brendolan A, Dan M, Piccinni P, La Greca G: Effects of different doses in continuous venovenous haemofiltration on outcomes of acute renal failure: a prospective randomised trial. Lancet 2000, 9223:26-30.

9. Schiffl $H$, Lang SM, Fischer R: Daily haemodialysis and the outcome of acute renal failure. $N$ Engl J Med 2002, 346:305-10.

10. Saudan P, Niederberger M, De Seigneux S, Romand J, Purgin J, Perneger T, Martin PY: Adding a dose of dialysis to continuous hemofiltration increases survival in patients with acute renal failure. Kidney Int 2006, 70:1312-7.

FI000 Factor 3.0 Recommended

Evaluated by Andrew Davenport 08 Nov 2006

II. Bouman CS, Oudemans-Van Straaten HM, Tijssen JG, Zandstra DF, Kesecioglu J: Effects of early high-volume continuous venovenous hemofiltration on survival and recovery of renal function in intensive care patients with acute renal failure: a prospective, randomized trial. Crit Care Med 2002, 30:2205-II.

12. Davenport A, Bouman C, Kirpalani A, Skippen P, Tolwani A, Mehta RL, Palevsky PM: Delivery of renal replacement therapy in acute kidney injury: what are the key issues? Clin J Am Soc Nephrol 2008, 3:869-75.

13. VA/NIH Acute Renal Failure Trial Network; Palevsky PM, Zhang JH, O'Connor TZ, Chertow GM, Crowley ST, Choudhury D, Finkel K, Kellum JA, Paganini E, Schein RM, Smith MW, Swanson KM, Thompson BT, Vijayan A, Watnick S, Star RA, Peduzzi P: Intensity of renal support in critically ill patients with acute kidney injury. N Engl J Med 2008, 359:7-20.

FI000 Factor 10.5 Exceptional

Evaluated by Achim Joerres 02 Jun 2008, Andrew Davenport 02 Jun 2008, John Laffey 03 Jun 2008, Greg Martin 04 Jun 2008, Giuseppe Remuzzi 25 Jul 2008, Heleen Oudemans-van Straaten 08 Aug 2008, William Mitch I4 Aug 2008

14. RENAL Replacement Therapy Study Investigators; Bellomo R, Cass A, Cole L, Finfer S, Gallagher M, Lo S, McArthur C, McGuinness S, Myburgh J, Norton R, Scheinkestel C, Su S: Intensity of continuous renal-replacement therapy in critically ill patients. $N$ EnglJ Med 2009, 36I: |627-38.

FI000 Factor 10.0 Exceptional

Evaluated by Paul Palevsky 28 Oct 2009, Achim Joerres 29 Oct 2009, Christof Westenfelder 10 Nov 2009, Andrew Davenport 23 Nov 2009, Bruce Bistrian 23 Nov 2009

15. Davenport A, Jones SR, Goel S, Astley JP, Hartog M: Differentiation of acute from chronic renal impairment by detection of carbamylated haemoglobin. Lancet 1993, 8861:1614-7.

16. Lobo DN, Bostock KA, Neal KR, Perkins AC, Rowlands BJ, Allison SP: Effect of salt and water balance on recovery of gastrointestinal function after elective colonic resection: a randomised controlled trial. Lancet 2002, 359:18|2-8.

17. Payen D, de Pont AC, Sakr Y, Spies C, Reinhart K, Vincent JL; Sepsis Occurrence in Acutely III Patients (SOAP) Investigators: A positive fluid balance is associated with a worse outcome in patients with acute renal failure. Crit Care 2008, I 2:R74.

18. Bouchard J, Soroko SB, Chertow GM, Himmelfarb J, Ikizler TA, Paganini EP, Mehta R; Program to improve care in acute renal disease (PICARD) study group: Fluid accumulation, survival and recovery of kidney function in critically ill patients with acute kidney injury. Kidney Int 2009, 76:422-7.

FI000 Factor 5.0 Must Read

Evaluated by Isaac Teitelbaum 24 Jun 2009, Valerie Luyckx 03 Sep 2009, Esteban Poch 22 Sep 2009, Robert Anderson 02 Nov 2009

19. Davenport A, Farrington K: Dialysis dose in acute kidney injury and chronic dialysis. Lancet 2010, 375:705-6.

20. Arieff Al: Fatal post operative pulmonary oedema. Pathogenesis and literature review. Chest 1999, I 15:1371-7. 